\title{
Treatment of drilling wastewater from a sulfonated mud system
}

\author{
Guo Jixiang ${ }^{1 *}$, Cui Yongjie ${ }^{2}$ and Cao Jingjing ${ }^{1}$ \\ ${ }^{1}$ Enhanced Oil Recovery Institute, China University of Petroleum, Beijing 102249, China \\ ${ }^{2}$ Shenghua Group Zhungeer Energy Co., Ltd, Inner Mongolia 010399, China \\ (C) China University of Petroleum (Beijing) and Springer-Verlag Berlin Heidelberg 2013
}

\begin{abstract}
Treatment of drilling wastewater from a sulfonated drilling mud system in the Shengli Oilfield, East China, was studied. The wastewater was deeply treated by a chemical coagulationcentrifugal separation-ozone catalytic oxidation combined process. The factors (i.e. $\mathrm{pH}$ value, chemical dosage, reaction time, etc.) influencing the treatment effect were investigated, and $\mathrm{pH}=7$ was determined as optimal for the coagulation; polymeric aluminum chloride (PAC) was selected as the optimal coagulant with a dosage of $18 \mathrm{~g} / \mathrm{L}$; cationic polyacrylamide (CPAM) with molecular weight of 8 million was selected as the optimal coagulant aid with an optimum dosage of $8 \mathrm{mg} / \mathrm{L}$; and the optimal condition of catalytic ozonation was found to be a $\mathrm{pH}$ of 12 and an oxidation time of $40 \mathrm{~min}$. The results showed that the combined treatment process was effective. The oil content and suspended solids content of the effluent reached the first class discharge standard according to China's standard GB 8978-1996 (Integrated Wastewater Discharge Standard) and the chemical oxygen demand (COD) decreased to $195 \mathrm{mg} / \mathrm{L}$ from $2.34 \times 10^{4} \mathrm{mg} / \mathrm{L}$ after coagulation process and ozone oxidation at $\mathrm{pH}=12$ for $40 \mathrm{~min}$.
\end{abstract}

Key words: Drilling wastewater, sulfonated mud system, coagulation and flocculation, centrifugal separation, ozone catalytic oxidation

\section{Introduction}

Drilling wastewater is highly diluted and complicated mixture of drilling mud containing various components of drilling fluid. From the viewpoint of the molecular structure of the organic treatment agents in the drilling fluid, these agents all contain carboxyl, phenolic hydroxyl, quinone, methyl formic acid and other functional groups, and there are various chromophoric groups and hydrophilic groups in their molecules. The drilling water is changeable and complex with a high content of suspended solids, highly colored, high chemical oxygen demand (COD), and a certain content of oil (Li and Zhang, 2010; Fan et al, 2002), resulting in treatment difficulties (Bundschuh et al, 2011; Asatekin and Mayes, 2009). Sulfonated mud treatment agents are usually used in wells deeper than $3,000 \mathrm{~m}$ for their high temperature resistance. The deeper the well, the more types and quantities of the treatment agents, and correspondingly, the more complicated the components of drilling wastewater. The high concentration of pollutants in the drilling wastewater can make the system stable, and lead to a high content of suspended solids, resulting in difficulty in treatment of the drilling wastewater. The wastewater was deeply treated by a

*Corresponding author. email: guojx002@163.com

Receiced August 16, 2012 chemical coagulation-centrifugal separation-ozone catalytic oxidation process in this work, and the influencing factors on the treatment effect were investigated.

\section{Materials and methods}

\subsection{Materials and instruments}

Drilling wastewater, from the Shengli Oilfield, East China; Coagulants: ferric chloride, aluminium chloride, polymeric ferric sulfate (PFS), polyaluminium chloride (PAC), polysilicate aluminium sulfate (PASS); Coagulant aids: nonionic polyacrylamide, cationic polyacrylamide (molecular weight range: 4-10 million); Ozone oxidation catalyst: selfmade (activated carbon supported by oxide nano particle of iron, manganese and copper). Drilling fluid additives: modified bitumen (KFT), valchovite (SPNH), sulfonated gilsonite (FT-1), sulfonated methyl phenolic resin (SMP-1), polyacrylamide (PAM).

pHS-3C acidimeter (INESA Scientific Instrument Co., Ltd, Shanghai, China); 5B-1 COD Rapid monitoring meter (Lanzhou Lianhua Environmental Protection Technology Co., Ltd, Lanzhou, China); HACH2100N turbidimeter (HACH, Danaher Corporation, USA); YQCF-G ozone generator (Yuqing Envirotech Co., Ltd, Changsha, China); CFY10 oxygen generator (Sumsun Ep Hi-tech., Co., Ltd, Beijing, China). 


\subsection{Methods}

\subsubsection{Methods for analysis of wastewater}

The chromaticity of the drilling wastewater was determined by the standard method, Water QualityDetermination of Colority (GB/T11903-1989, China) (Xuan et al, 2010). The COD was determined by fast digestspectrophotometry using a 5B-1 COD rapid monitoring meter. The $\mathrm{pH}$ value was determined using a $\mathrm{pHS}-3 \mathrm{C}$ acidimeter. The 5-day bacterial oxygen demand (BOD5) was measured by the standard method, Water Quality-Determination of Biochemical Oxygen Demand after 5 days $\left(\mathrm{BOD}_{5}\right)$, for dilution and seeding method (HJ505-2009, China); and the turbidity was measured using a turbidimeter.

\subsubsection{Chemical coagulation}

Drilling wastewater $(100 \mathrm{~mL})$ was put in a beaker, and the $\mathrm{pH}$ was adjusted to 7 , then coagulant was added into the beaker at a stirring speed of $250 \mathrm{r} / \mathrm{min}$ for $2 \mathrm{~min}$, and then coagulant aid was added into the beaker at a stirring speed of $60 \mathrm{r} / \mathrm{min}$ for $5 \mathrm{~min}$. The coagulation process was carried out at ambient temperature.

\subsubsection{Centrifugal separation}

The drilling wastewater after the coagulation process was separated in a centrifuge at a speed of 2,000 r/min for 5 min, and then the upper part of the centrifuge was analyzed (turbidity, COD, etc.).

\subsubsection{Ozone catalytic oxidation}

The $\mathrm{pH}$ of the effluent of drilling wastewater after treatment by the "chemical coagulation-centrifugal separation" process, that is, the $\mathrm{pH}$ value of the upper part of the centrifugal separation process, was adjusted to 7 . Then the effluent was put into the ozone generator with the ozone oxidation catalyst for ozone catalytic oxidation, using the oxygen enriched air generated by CFY10 oxygen generator as air source, and the ozone enriched oxygen entered from the bottom of the ozone generator.

\section{Results and discussion}

\subsection{Analysis of drilling wastewater}

The analysis results of the drilling wastewater, from the Shengli Oilfield, East China, are presented in Table 1.

Table 1 Analysis result of the drilling wastewater

\begin{tabular}{cccccc}
\hline $\mathrm{pH}$ & Chromaticity & $\begin{array}{c}\mathrm{COD} \\
\mathrm{mg} / \mathrm{L}\end{array}$ & $\begin{array}{c}\text { BOD } \\
\mathrm{mg} / \mathrm{L}\end{array}$ & $\begin{array}{c}\text { Solids content } \\
\mathrm{mg} / \mathrm{L}\end{array}$ & $\begin{array}{c}\text { Oil content } \\
\mathrm{mg} / \mathrm{L}\end{array}$ \\
\hline 8.45 & 1000 & $2.34 \times 10^{4}$ & $1.11 \times 10^{4}$ & 344 & 35.67 \\
\hline
\end{tabular}

Table 1 shows that the drilling wastewater was alkaline with high chromaticity. The suspended solids content and oil content were 344 and $35.7 \mathrm{mg} / \mathrm{L}$, respectively, and the COD was up to $2.34 \times 10^{4} \mathrm{mg} / \mathrm{L}$, all being higher than the discharge standard (GB8978-1996). Thus, treatment of the drilling wastewater is needed to meet the requirements for wastewater discharge.

\subsection{Chemical coagulation}

Chemical coagulation is an aggregation process of the colloidal particles and small suspended matter in the wastewater, by destabilizing the colloidal particles as a function of the coagulant, namely electrostatic neutralization, adsorption, bridging, etc. (Yang et al, 2004; Wang et al, 2008; Tao et al, 2011; Niu et al, 2011).

\subsubsection{Selection of coagulant}

The optimal coagulant was selected from five commonly used coagulants (i.e. ferric chloride, aluminium chloride, polymeric ferric sulfate (PFS), polyaluminium chloride (PAC), polysilicate aluminium sulfate (PASS)) (Zhang et al, 2008; Yang et al, 2010): Different coagulants (16 mL, 10 $\mathrm{wt} \%$ ) was added separately, and coagulant aid (PAM) (2 mg/ L) was added, into the drilling wastewater $(100 \mathrm{~mL})$. The optimal coagulant was selected by taking the turbidity and COD removal rate as the evaluation indices after the drilling wastewater was treated by coagulation and centrifugal separation.

The COD removal rate is defined as below (Chen et al, 2010; Meng and Fan, 2011):

$$
\text { COD removal rate }(\%)=\frac{(\mathrm{COD})_{0}-\mathrm{COD}}{(\mathrm{COD})_{0}} \times 100 \%
$$

where (COD) $)_{0}$ stands for the initial COD value of the drilling wastewater; COD stands for the residual COD value of the drilling wastewater after treatment by coagulation process.

The turbidity and COD removal rate of the drilling wastewater treated with different coagulants are shown in Table 2 .

Table 2 COD removal rate and turbidity of the drilling wastewater treated with different coagulants

\begin{tabular}{ccc}
\hline Coagulant & Turbidity, NTU & COD removal rate, \% \\
\hline $\mathrm{FeCl}_{3}$ & 14.6 & 78 \\
$\mathrm{AlCl}_{3}$ & 13.8 & 75 \\
$\mathrm{PAC}$ & 8.3 & 90 \\
$\mathrm{PFS}$ & 10.5 & 83 \\
PASS & 11.2 & 80 \\
\hline
\end{tabular}

Table 2 shows that among the five coagulants, PAC showed the best effect with the lowest turbidity and highest COD removal rate, thus, PAC was selected as the optimal coagulant for the drilling wastewater treatment.

\subsubsection{Selection of coagulant aid PAMs}

PAC (16 mL, 10wt\%) was added to $100 \mathrm{~mL}$ of drilling wastewater, then $1 \mathrm{~mL}(200 \mathrm{mg} / \mathrm{L})$ of different types of PAMs (nonionic and cationic PAM, with an average relative molecular weight of 4 million, 8 million and 12 million, respectively) were separately added into the drilling wastewater. The optimal coagulant aid was selected by taking the turbidity and COD as the evaluation indices after the drilling wastewater was treated by coagulation process and centrifugal separation. The results are presented in Table 3.

As shown in Table 3, the effect of drilling wastewater treatment with cationic PAM was better than that with 
nonionic PAM at the same PAM molecular weight, and cationic PAM with a molecular weight of 8 million had the best effect among these cationic PAMs. Therefore, cationic PAM with a molecular weight of 8 million was selected as the optimal coagulant aid for the drilling wastewater treatment.

Table 3 Flocculation effect of nonionic and cationic PAMs with different relative molecular weight

\begin{tabular}{cccc}
\hline Coagulant aid & Molecular weight & $\begin{array}{c}\text { Turbidity } \\
\text { NTU }\end{array}$ & $\begin{array}{c}\text { COD removal rate } \\
\%\end{array}$ \\
\hline \multirow{3}{*}{ Nonionic PAM } & 4 million & 8.76 & 82.6 \\
& 8 million & 7.63 & 84.9 \\
& 12 million & 8.36 & 85.1 \\
\hline \multirow{2}{*}{ Cationic PAM } & 4 million & 7.14 & 83.8 \\
& 8 million & 6.55 & 87.4 \\
& 12 million & 7.94 & 85.2 \\
\hline
\end{tabular}

\subsubsection{Effect of $\mathrm{pH}$}

The $\mathrm{pH}$ value of $80 \mathrm{~mL}$ drilling wastewater was adjusted to $4.0,5.0,6.0,7.0,8.0$, and 9.0 respectively using $\mathrm{HCl}$ and $\mathrm{NaOH}$, then $12 \mathrm{~mL}(10 \mathrm{wt} \%)$ of PAC was added to the drilling wastewater with different $\mathrm{pH}$ values, the effect of $\mathrm{pH}$ was evaluated by measuring the turbidity and COD removal rate of the drilling wastewater after treatment by coagulation process and centrifugal separation. The results are shown in Fig. 1.

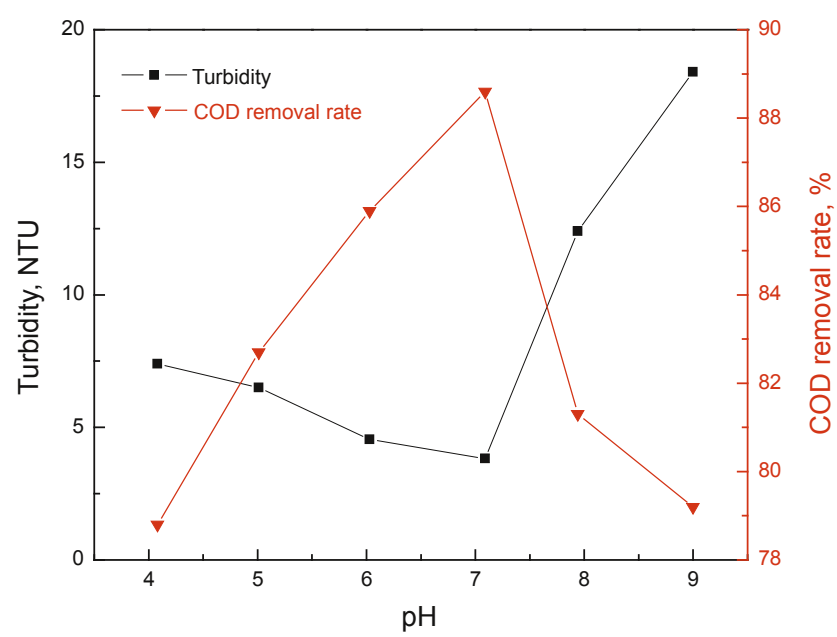

Fig. 1 Effect of $\mathrm{pH}$ on the COD removal rate and turbidity of the drilling wastewater

As shown in Fig. 1, the COD removal rate was low at low $\mathrm{pH}$ values, which was because at low $\mathrm{pH}$ values, the product was mainly a complex with high charge and low polymerization degree. This could not play the adsorption bridging role, leading to a low COD removal rate. When the $\mathrm{pH}$ was greater than 7, the flocculation effect was also poor, showing high turbidity and low COD removal rate. This was mainly because that the formed colloids can be redissolved and so cannot assist with the coagulation. When the $\mathrm{pH}$ was 7, the treated wastewater had the lowest turbidity and the highest $\mathrm{COD}$ removal rate, therefore, $\mathrm{pH}=7$ was determined as the optimal $\mathrm{pH}$ value for the coagulation.

\subsubsection{Determination of optimum dosage of coagulant}

The $\mathrm{pH}$ value of the drilling wastewater was adjusted to 7.0 , then different amounts of PAC were added to $80 \mathrm{~mL}$ of the drilling wastewater to obtain PAC concentrations of 6.4, 9.6, 11.2, 12.8, 14.4, 16.0 and $19.2 \mathrm{~g} / \mathrm{L}$, the optimum dosage of coagulant was determined by measuring the turbidity and COD removal rate of the drilling wastewater treated by coagulation process and centrifugal separation. The results are shown in Fig. 2.

Fig. 2 shows that the effluent had a relatively low turbidity value and a relatively high COD removal rate when the dosage of PAC was $18 \mathrm{~g} / \mathrm{L}$, and the treatment effect increased slightly with a further increase in the PAC dosage. Considering the treatment cost, $18 \mathrm{~g} / \mathrm{L}$ was recommended as the optimum dosage of PAC.

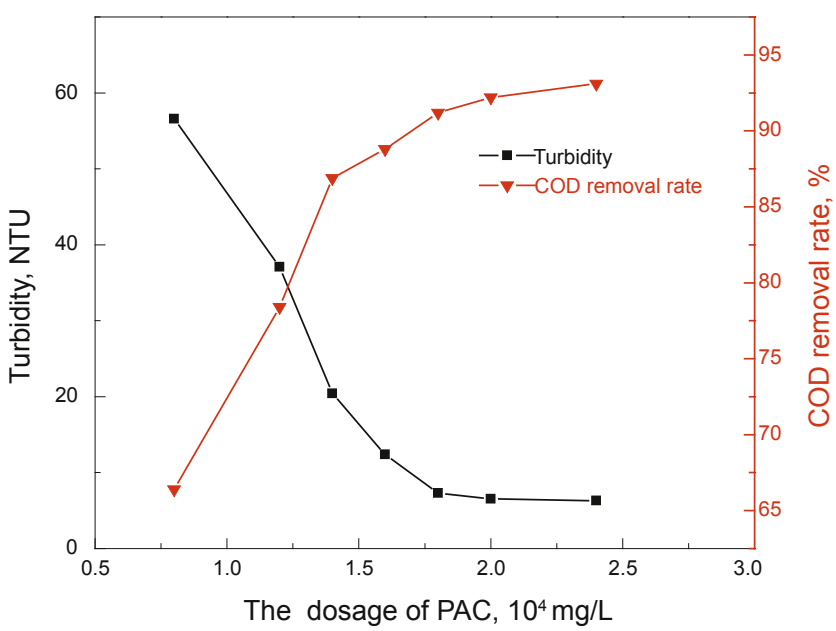

Fig. 2 Effect of PAC dosage on COD removal rate and turbidity of the drilling wastewater

\subsubsection{Determination of optimum dosage of coagulant aid}

Cationic PAM with a molecular weight of 8 million was selected as the optimal coagulant aid, and the optimum dosage of PAM was determined. The results are shown in Fig. 3.

The effluent had a relatively low turbidity value and a relatively high COD removal rate at a PAM dosage of $8 \mathrm{mg} /$ L (Fig. 3), and there was no significant change in turbidity and the COD removal rate with further increase of the PAM dosage. Therefore, an $8 \mathrm{mg} / \mathrm{L}$ dosage of PAM was recommended.

The main properties of the effluent after wastewater was treated by coagulation process and centrifugal separation were determined. The coagulation treatment was conducted at the optimum condition as follows: The $\mathrm{pH}$ of the drilling wastewater was at 7 , the dosages of PAC and PAM were $1.8 \times 10^{4} \mathrm{mg} / \mathrm{L}$ and $8 \mathrm{mg} / \mathrm{L}$ respectively. The results of coagulation treatment of wastewater are shown in Table 4.

After coagulation and centrifugal separation, the oil content and suspended solids content in the effluent of the drilling wastewater were relatively low, meeting the discharge standard (GB 8978-1996). However, the residual COD was $750 \mathrm{mg} / \mathrm{L}$, which was still high. The drilling wastewater needed further treatment. 
Table 4 Analysis result of the drilling wastewater after treatment by coagulation process and centrifugal separation

\begin{tabular}{cccc}
\hline Chromaticity & $\begin{array}{c}\text { Content of } \\
\text { suspended solid } \\
\mathrm{mg} / \mathrm{L}\end{array}$ & $\begin{array}{c}\text { Oil content } \\
\mathrm{mg} / \mathrm{L}\end{array}$ & $\begin{array}{c}\mathrm{COD} \\
\mathrm{mg} / \mathrm{L}\end{array}$ \\
\hline 70 & 35 & 8 & 750 \\
\hline
\end{tabular}

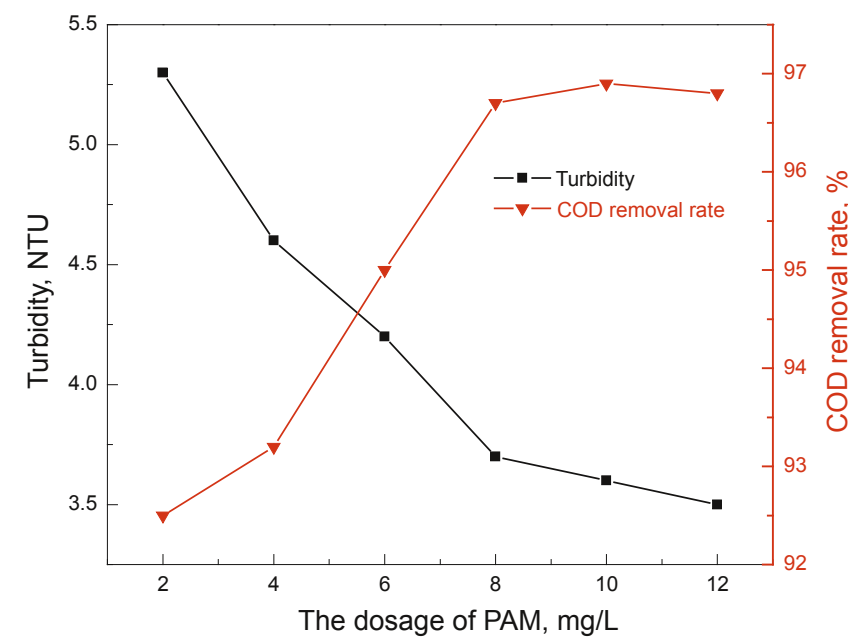

Fig. 3 Effect of the PAM dosage on COD removal rate and turbidity of drilling wastewater

\subsubsection{Reason why the COD value is still high after flocculation treatment}

The coagulation characteristics of the main drilling fluid additives were investigated to study the high residual COD value of sulfonated mud drilling wastewater after treatment. Different amounts of PAC were added to drilling fluid additives solution containing $0.1 \mathrm{wt} \%$ additives, and the influence of different drilling fluid additives on the coagulation treatment effect at different PAC concentrations was investigated.

As shown in Fig. 4, the PAC showed different effects in the coagulation treatment of the six drilling fluid additives solutions: the best treatment effect for FT-1, with a COD removal rate of $98 \%$; the second treatment effect for KFT and SPNH, and the worst treatment effect for SMP-1. This is mainly because the sulfonation group has a strong hydratability, a high solubility, and is hard to be removed by coagulation, leading to the high COD value after coagulation.

\subsection{Ozone catalytic oxidation}

Ozonation has the merits of strong oxidation capacity, high reaction rate, and no secondary pollution in water treatment $(\mathrm{Lu}$ et al, 2002; Xi and Liu 2005; Yu et al, 2008). Ozone catalytic oxidation is an advanced oxidation technology for wastewater treatment and was developed from the chemical oxidation (Li et al, 2012; Rocha et al, 2012). It has become a research focus for its simple process, repeated use and regeneration of catalyst, no secondary pollution, etc. (Guan et al, 2007; Xiong et al, 2010; Lafi et al, 2009).

3.3.1 Effects of oxidation time and catalyst on treatment of wastewater

The influence of oxidation time and catalyst on COD

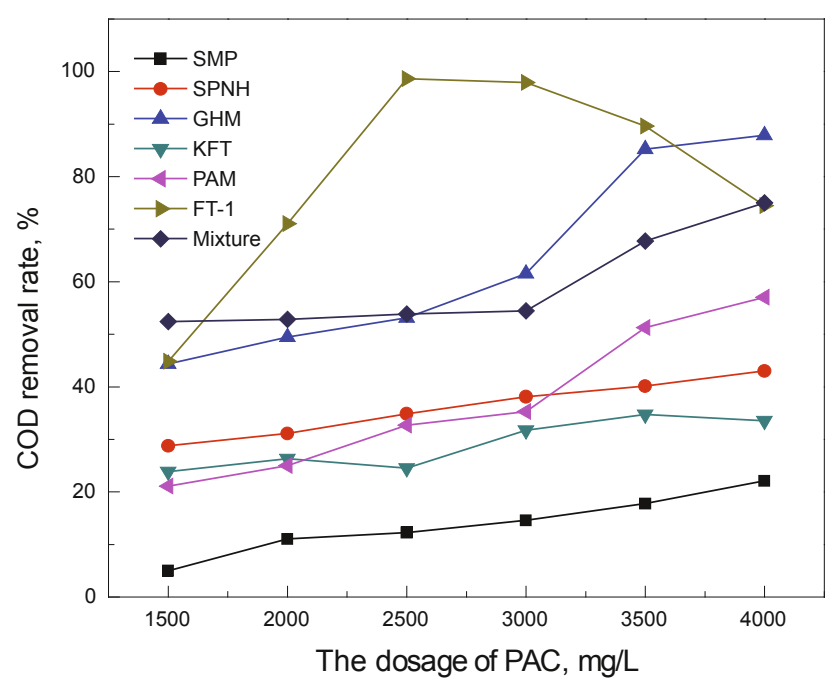

Fig. 4 Coagulation effects of six drilling fluid additives

reduction was studied with drilling wastewater at $\mathrm{pH}=7.0$ after coagulation-centrifugal separation processes.

As shown in Fig. 5, the COD removal rate of the drilling wastewater by the catalytic ozonation was higher than that by ozone oxidation. The COD removal rate initially increased rapidly with increasing oxidation time, and then increased only slightly after the oxidation time exceeded $40 \mathrm{~min}$. The highest COD removal rate of the drilling wastewater reached $61 \%$ by the catalytic ozonation, and the residual COD of it was still high $(285 \mathrm{mg} / \mathrm{L})$ after catalytic ozonation, thus, the investigation of influence of $\mathrm{pH}$ on ozonation effect was needed.

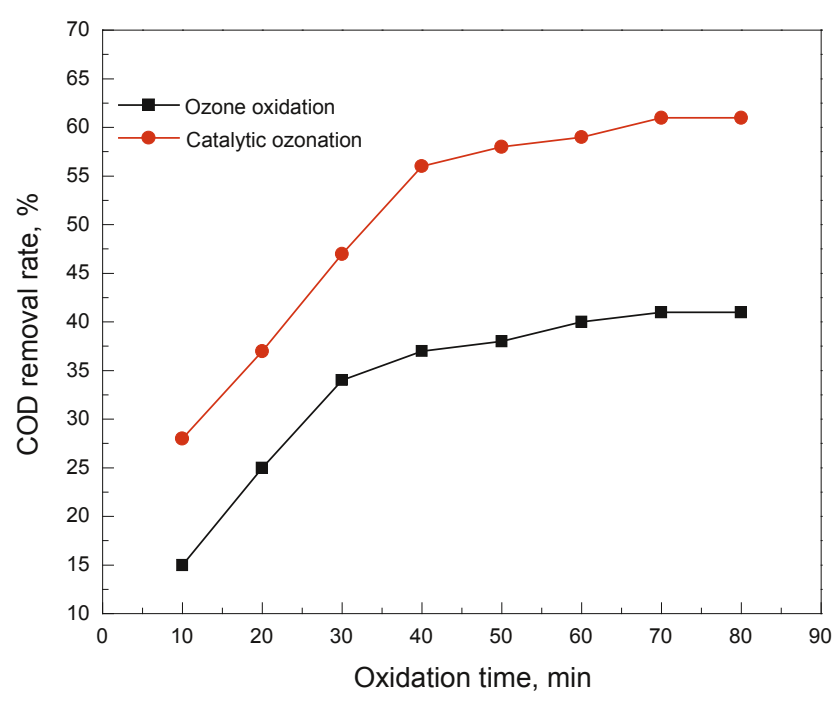

Fig. 5 The effect of ozone oxidation and catalytic ozonation with time

\subsubsection{Influence of pH on ozonation treatment}

The $\mathrm{pH}$ value of the drilling wastewater was adjusted to $5.0,6.0,7.0,8.0,9.0$ and 12.0 , respectively. Then the influence of $\mathrm{pH}$ on the ozonation treatment of the drilling wastewater was studied at an oxidation time of $40 \mathrm{~min}$. The results are shown in Fig. 6. 


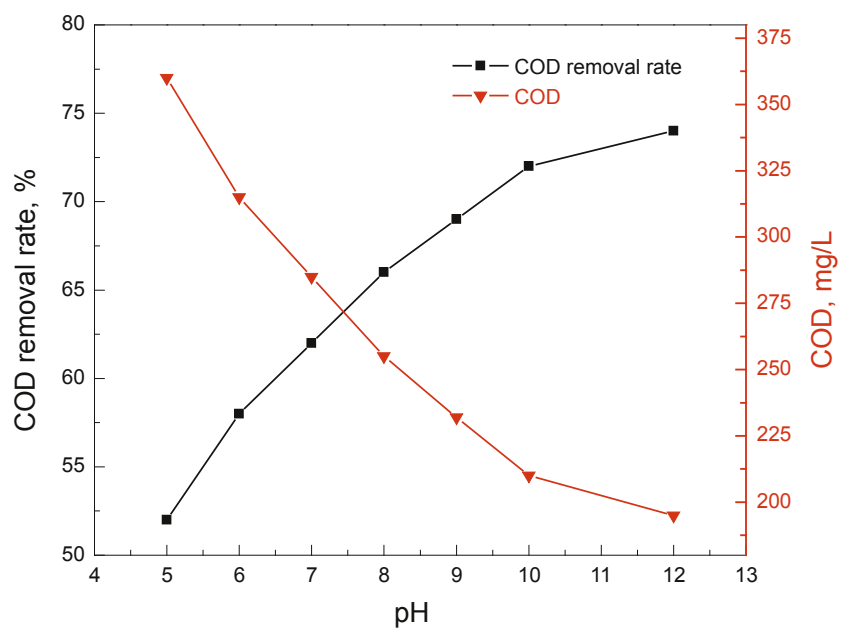

Fig. 6 Results of oxidation treatment of drilling wastewater at different $\mathrm{pH}$ values

The COD removal rate of the drilling wastewater increased with increasing $\mathrm{pH}$ (Fig. 6), indicating that the oxidation decomposition of the organic compounds in the drilling wastewater increased. When the $\mathrm{pH}$ of drilling wastewater was 12 , the COD removal rate reached $74 \%$ and the residual COD of the effluent was $195 \mathrm{mg} / \mathrm{L}$, indicating that the organic compounds in the drilling wastewater cannot be fully decomposed by catalytic ozonation. After the treatment of catalytic ozonation, the $\mathrm{pH}$ of the effluent should be adjusted at the range of 6-9 to meet the requirement of $\mathrm{pH}$ value of outer drainage in China's standard GB 8978-1996.

The effluent was analyzed after the drilling wastewater was treated by the chemical coagulation-centrifugal separation-ozone catalytic oxidation process, and the results are shown in Table 5.

Table 5 Analysis result of the effluent after the drilling wastewater was treated by the combined process

\begin{tabular}{cccc}
\hline Chromaticity & $\begin{array}{c}\text { Content of suspended } \\
\text { solid, mg/L }\end{array}$ & $\begin{array}{c}\text { Oil content } \\
\mathrm{mg} / \mathrm{L}\end{array}$ & $\begin{array}{c}\mathrm{COD} \\
\mathrm{mg} / \mathrm{L}\end{array}$ \\
\hline 15 & 24 & 2 & 195 \\
\hline
\end{tabular}

As shown in Table 5, after the wastewater was treated by the chemical coagulation-centrifugal separation-ozone catalytic oxidation process, the oil content and the suspended solids content of the effluent reached the first class discharge standard according to China's standard GB 8978-1996 (Integrated Wastewater Discharge Standard), and the COD decreased to $195 \mathrm{mg} / \mathrm{L}$ from $2.34 \times 10^{4} \mathrm{mg} / \mathrm{L}$ (Table 1).

\section{Conclusions}

1) The introduction of sulfonation groups to the drilling fluid additives enhances its hydrostability and solubility, and these sulfonation groups are hard to be removed by coagulation, resulting in high residual COD value after coagulation.

2) The optimum operation parameters of the chemical coagulation-centrifugal separation-ozone catalytic oxidation combined process were determined: PAC was selected as the optimal coagulant and its optimum dosage was $18 \mathrm{~g} /$ $\mathrm{L}$; cationic PAM with a molecular weight of 8 million was selected as the optimal coagulant aid and its recommended dosage was $8 \mathrm{mg} / \mathrm{L}$ and the optimal $\mathrm{pH}$ value for the coagulation was 7 . The optimal conditions for catalytic ozonation was at a $\mathrm{pH}$ of 12 and an oxidation time of $40 \mathrm{~min}$.

3) The COD removal rate increased with the increase of the $\mathrm{pH}$ value in the ozone catalytic oxidation, the COD removal rate reached $61 \%$ and the residual COD was less than $200 \mathrm{mg} / \mathrm{L}$ after oxidation when the $\mathrm{pH}$ was 12 and the oxidation time lasted for $40 \mathrm{~min}$.

4) The oil content and suspended solids content of the effluent reached the first class discharge standard according to China's standard GB 8978-1996 (Integrated Wastewater Discharge Standard) and the chemical oxygen demand (COD) decreased below $200 \mathrm{mg} / \mathrm{L}$ from $2.34 \times 10^{4} \mathrm{mg} / \mathrm{L}$, the total COD removal rate reached $99.1 \%$ after the combined process of chemical coagulation-centrifugal separation-ozone catalytic oxidation.

\section{Acknowledgements}

The authors would like to thank the National High Technology Research and Development Program of China (No. 2013AA064301), and National Natural Science Foundation of China (No. 51274210) for financial support.

\section{References}

Asatekin A and Mayes A M. Oil industry wastewater treatment with fouling resistant membranes containing amphiphilic comb copolymers. Environmental Science \& Technology. 2009. 43: 4487 4492

Bundschuh M, Pierstorf R, Schreiber W H, et al. Positive effects of wastewater ozonation displayed by in situ bioassays in the receiving stream. Environmental Science \& Technology. 2011. 45: 3774-3780

Chen Y, Xie Z F, Zhu W R et al. Coagulation treatment of highconcentration wastewater of washing for ready-made clothes. Environmental Science and Technology. 2010. 33(4): 133-136 (in Chinese)

Fan Q Y, He H J and Wang Y H. Progress in treatments of drilling, acidizing and hydrofracturing wastewaters in China. Oilfield Chemistry. 2002. 19(04): 387-390 (in Chinese)

Guan C Y, Ma J and Bao X L. Studies on efficiency of catalytic ozonation-gac processes for the purification of micro-polluted source water. Technology of Water Treatment. 2007. 33(11): 75-78 (in Chinese)

Lafi W K, Shannak B, Al-Shannag M, et al. Treatment of olive mill wastewater by combined advanced oxidation and biodegradation. Separation and Purification Technology. 2009. 70(02): 141-146

Li L and Zhang L S. Technology and research of drilling wastewater treatment in the Oilfields. Technology Supervision in Petroleum Industry. 2010. 26(01): 23-26 (in Chinese)

Li X H, Dou X M and Li J Q. Antimony(V) removal from water by ironzirconium bimetal oxide: Performance and mechanism. Journal of Environmental Science. 2012. 24(7): 1197-1203

Lu N C and Fu L M. Study on treating high concentration organic wastewater by the ozone oxide method. Pollution Control Technology. 2002. 15(02): 11-12 (in Chinese)

Meng X L and Fan X D. Study on treatment of dye wastewater by sludge 
activated carbon. Environmental Science and Management. 2011. 36(7): 67-72 (in Chinese)

Niu X X, Li X L, Zhao J H, et al. Preparation and coagulation efficiency of polyaluminium ferric silicate chloride composite coagulant from wastewater of high-purity graphite production. Journal of Environmental Science. 2011. 23(7): 1122-1128

Rocha J H B, Gomes M M S, Fernandes N S et al. Application of electrochemical oxidation as alternative treatment of produced water generated by Brazilian petrochemical industry. Fuel Processing Technology. 2012. 96: 80-87

Tao L L, Li P, Ding J M, et al. The chemical coagulation-advanced oxidation composite process for treating sulfur-contained tannery wastewater. Leather and Chemicals. 2011. 28(6): 8-9 (in Chinese)

Wang Y, Gao B Y, Yue Q Y, et al. The characterization and flocculation efficiency of composite flocculant iron saltspolydimethyldiallylammoniumchloride. Chemical Engineering Journal. 2008. 142(2): 175-181

Xi C W and Liu B B. Treatment for hardly degraded organic wastewater with ozone oxidization method. Industrial Safety and Dust Control. 2005. 31(11): 15-16 (in Chinese)
Xiong Z L, Cheng X and Sun D Z. Pretreatment of heterocyclic pesticide wastewater using ultrasonic/ozone combined process. Journal of Environmental Science. 2010. 23(5): 725-730

Xuan Z F, Zhang S J, Tan P G et al. Water quality idea discussion on determination of colority-dilution method. Arid Environmental Monitoring. 2010. 24(2): 126-128 (in Chinese)

Yang Y W, Qian J W and Shen Z Q. A novel flocculant of $\mathrm{Al}(\mathrm{OH})_{3}$ polyacrylamide ionic hybrid. Journal of Colloid Interface Science. 2004. 273: 400-405

Yang Z, Gao B and Yue Q. Coagulation performance and residual aluminum speciation of $\mathrm{Al}_{2}\left(\mathrm{SO}_{4}\right)_{3}$ and polyaluminum chloride (PAC) in Yellow River water treatment. Chemical Engineering Journal. 2010. 165: 122-132

Yu Y Z, Tan J and Feng Y. Application of ozone-combined process in water treatment. Industrial Water \& Wastewater. 2008. 39(3): 8-11 (in Chinese)

Zhang P, Wu Z, Zhang G, et al. Coagulation characteristics of polyaluminum chlorides $\mathrm{PAC}-\mathrm{Al}_{30}$ on humic acid removal from water. Separation and Purification Technology. 2008. 63: 642-647

(Edited by Zhu Xiuqin) 